Check for updates

Cite this: Chem. Sci., 2019, 10, 2280

๑ All publication charges for this article have been paid for by the Royal Society of Chemistry

Received 22nd October 2018

Accepted 18th December 2018

DOI: $10.1039 / \mathrm{c} 8 \mathrm{sc} 04705 \mathrm{~g}$

rsc.li/chemical-science

\section{Synergistic self-seeding in one-dimension: a route to patchy and block comicelles with uniform and controllable length $\uparrow$}

\author{
Jiangping Xu, (D) ac Hang Zhou, ${ }^{a}$ Qing Yu, ${ }^{a}$ Gerald Guerin, ${ }^{a}$ Ian Manners ${ }^{b}$ \\ and Mitchell A. Winnik (D) *a
}

\begin{abstract}
Self-seeding is a process unique to polymer crystals, which consist of regions of different chain packing order and different crystallinity. Here we report the synergistic self-seeding behaviour of pairs of corecrystalline block copolymer (BCP) micelle fragments and show how this strategy can be employed to control the morphology of these BCP comicelles. Each micelle fragment has a critical dissolution temperature $\left(T_{\mathrm{c}}\right)$, and unimers of each BCP have a characteristic epitaxial growth rate. The $T_{\mathrm{c}}$ value affects the dissolution sequence of the fragments upon heating, while the unimer growth rate affects the growth sequence upon cooling. By carefully choosing micelle fragments having different $T_{\mathrm{c}}$ values as well as growth rates, we could prepare patchy comicelles and block comicelles with uniform and controllable length. This synergistic self-seeding strategy is a simple yet effective route to control both length and morphology of core-crystalline comicelles
\end{abstract}

\section{Introduction}

Cylindrical micelles of block copolymers (BCPs) have important applications in drug delivery, ${ }^{\mathbf{1 - 3}}$ epoxy resin toughening, ${ }^{\mathbf{4}}$ and templates for hybrid materials. ${ }^{5}$ Other applications may be possible if one could control their core/corona structure as well as their length. Various groups have examined $\mathrm{AB} / \mathrm{AC}$ diblock copolymer blends and $\mathrm{ABC}$ triblock copolymers as ways to obtain different core or corona structures. ${ }^{6-11}$ These micelle structures can be manipulated by changing the blend ratio, the block ratio or the self-assembly protocol. However, it is a challenge to control the micelle length, and cylindrical micelles with broad length distributions are usually obtained. ${ }^{\mathbf{1 2}}$

Recently, crystallization-driven self-assembly (CDSA) has become a powerful strategy to control both the length and the structure of cylindrical micelles. ${ }^{\mathbf{1 3 - 2 4}}$ Like an initiator of living chain polymerization of monomers, a seed micelle with a crystalline core can direct the epitaxial deposition of the newly added BCP unimers (seeded-growth). The length of the cylindrical micelles can be controlled precisely by changing the

\footnotetext{
${ }^{a}$ Department of Chemistry, University of Toronto, 80 St. George Street, Toronto, ON, M5S 3H6, Canada.E-mail: mwinnik@chem.utoronto.ca

${ }^{b}$ School of Chemistry, University of Bristol, Bristol, BS8 1TS, UK

${ }^{c}$ Key Laboratory of Material Chemistry for Energy Conversion and Storage, Ministry of Education, School of Chemistry and Chemical Engineering, Huazhong University of Science and Technology (HUST), Wuhan 430074, China

$\dagger$ Electronic supplementary information (ESI) available: Experimental details, self-seeding kinetics, TEM images of stained micelles, additional figures of the patchy and block comicelles (Fig. S1-S16), and fraction of surviving fragments at different temperatures (Table S1). See DOI: 10.1039/c8sc04705g
}

unimer-to-seed ratio. ${ }^{16,20}$ Moreover, one can manipulate the crystallization kinetics to control the morphology of cylindrical micelles. ${ }^{25-28}$ For example, in the seeded-growth process, a slow crystallization rate leads to linear micelles, while a rapid crystallization rate can lead to branched micelles. ${ }^{25}$ In addition, by sequential addition of unimers bearing different corona chains, block comicelles can be obtained, ${ }^{\mathbf{1 9 , 2 0}}$ while simultaneous addition of pairs of different unimers leads to patchy micelles characterized by phase-segregation into nano-sized local patches. $^{23,27,28}$

We are interested in developing methodologies to construct well-defined morphologies of cylindrical micelles by manipulating their crystallization behaviour. Several years ago, we discovered that "self-seeding" of BCP micelle crystallites was an effective means to control micelle length. ${ }^{\mathbf{1 4 , 2 9 , 3 0}}$ Self-seeding is a phenomenon unique to polymer crystals, which consist of regions of different chain packing order and different crystallinity, and thus a broad range of melting temperatures. ${ }^{31,32}$ Upon heating, the least crystalline domains are the first to melt or dissolve, while the most crystalline domains are the last to survive. These surviving nuclei serve as initiators to direct the crystal growth upon cooling. ${ }^{32}$ Our initial examples involved annealing solutions of polyferrocenyldimethylsilane (PFS)containing BCP micelle fragments (length: $\sim 50 \mathrm{~nm}$ ) above an onset temperature, followed by cooling to room temperature. ${ }^{29,30}$ Uniform rod-like micelles were formed, of which the length was sensitive to the annealing temperature $\left(T_{\mathrm{a}}\right)$. This strategy has also been extended to other BCPs with other crystallizable blocks, such as polycaprolactone, ${ }^{21,33}$ poly(3- 
hexylthiophene $)^{14}$ and oligo( $p$-phenylenevinylene $),{ }^{34}$ and BCPs with a liquid crystalline block. ${ }^{35}$

Although self-seeding is effective for controlling the length of cylindrical micelles, it has not been used for morphology control. Control over morphology in a self-seeding experiment requires an understanding of the factors that affect both the dissolution step upon heating and the growth rate upon cooling. Here we examine the self-seeding behaviour of mixtures of micelle fragments and use kinetic studies of seeded growth to model the regrowth step. Based upon this understanding of the dissolution and regrowth steps, we designed experiments on mixtures of micelle fragments that allow us to control both the length and morphology of the micelles obtained.

\section{Results and discussion}

We began by examining the self-seeding behaviour of each type of micelle fragment (Fig. 1). These include three PFS- $b$-P2VP samples ( $\mathrm{P} 2 \mathrm{VP}=\operatorname{poly}(2$-vinylpyridine) $): \mathrm{PFS}_{17}-b$ - $\mathrm{P}_{2} \mathrm{VP}_{170}\left(L_{0}=\right.$ $43 \mathrm{~nm}), \mathrm{PFS}_{25}-b-\mathrm{P}_{2} \mathrm{VP}_{330}\left(L_{0}=49 \mathrm{~nm}\right)$, and $\mathrm{PFS}_{35}-b-\mathrm{P} 2 \mathrm{VP}_{400}\left(L_{0}=\right.$ $52 \mathrm{~nm}$ ) (Chart S1 and Fig. S1 in ESI $\dagger$ ). Typically, aliquots (0.5 $\mathrm{mL})$ of a micelle fragment solution $\left(0.02 \mathrm{mg} \mathrm{mL}^{-1}\right)$ in 2-propanol were heated at different temperatures for $30 \mathrm{~min}$ and then cooled to room temperature and aged for 1 day (see ESI $\dagger$ ). We recently showed that self-seeding is characterized by a critical dissolution temperature $\left(T_{\mathrm{c}}\right)$ corresponding to the temperature at which the initial average micelle length $\left(L_{0}\right)$ doubled upon cooling (to $2 L_{0}$ ). ${ }^{36}$ When the annealing temperature $T_{\mathrm{a}}>T_{\mathrm{c}}$, the average length of the micelles $\left(L_{n}\right)$ increased sharply as a function of temperature (Fig. 1 and S2-S6 + ). These PFS- $b$-P2VP samples showed very different $T_{\mathrm{c}}$ values (Fig. 1b): for $\mathrm{PFS}_{17}-b$ $\mathrm{P} \mathrm{VP}_{170}, T_{\mathrm{c}}=35{ }^{\circ} \mathrm{C}$; for $\mathrm{PFS}_{25}-b-\mathrm{P}_{2} \mathrm{VP}_{330}, T_{\mathrm{c}}=55^{\circ} \mathrm{C}$; and for $\mathrm{PFS}_{35}-b$ - $\mathrm{P}_{2} \mathrm{VP}_{400}, T_{\mathrm{c}}=67{ }^{\circ} \mathrm{C}$. The difference in $T_{\mathrm{c}}$ may be attributed to the difference in PFS length, as the increase in PFS length will decrease its solubility upon heating.

Then we examined the self-seeding behaviour of $\mathrm{PFS}_{26}-b$ $\operatorname{PNIPAM}_{190}\left(\mathrm{PNIPAM}=\operatorname{poly}(N\right.$-isopropylacrylamide $), L_{0}=52$ $\mathrm{nm})$ and PFS $_{26}-b$-PNIPAM ${ }_{520}\left(L_{0}=50 \mathrm{~nm}\right)$ fragments. As shown in Fig. 1c, for $\mathrm{PFS}_{26}-b$-PNIPAM $190, T_{\mathrm{c}}=61^{\circ} \mathrm{C}$; while for $\mathrm{PFS}_{26}-b$ PNIPAM $_{520}, T_{\mathrm{c}}=65^{\circ} \mathrm{C}$. Although the lengths of PNIPAM block

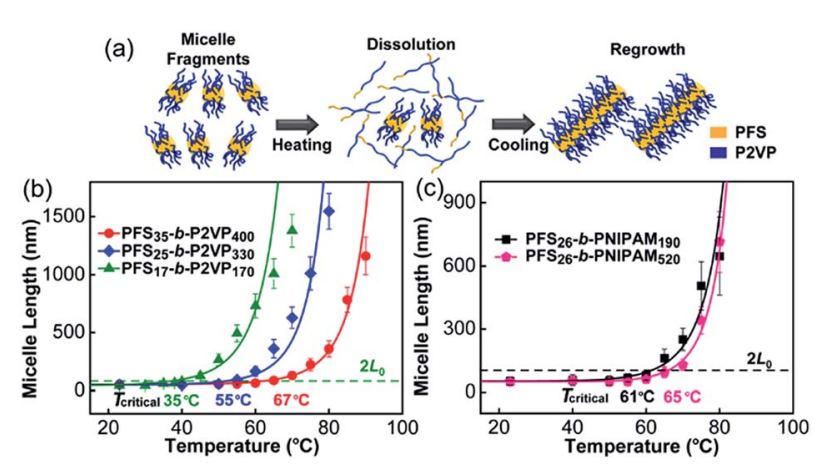

Fig. 1 Self-seeding behaviour of single kinds of micelle fragments. (a) A schematic diagram of the self-seeding process. (b) and (c) show the increase in micelle length as a function of annealing temperature. The fitted curves were calculated as described in ref. 36 . are very different, the $T_{\mathrm{c}}$ of these two fragments are similar, confirming that the length of PFS block plays a more important role in determining $T_{\mathrm{c}}$. It is worth noting that there is an upper limit of the annealing temperature for each self-seeding experiment. When the fragments were heated at a temperature above this limit, branched micelles were formed as the solution cooled (Fig. S2-S6†). The formation of branched structures under these conditions suggests a different dissolutionregrowth mechanism, a topic now under investigation.

On the basis of the above results, we designed self-seeding experiments on micelle fragment mixtures. We initially investigated the self-seeding behaviour of pairs of micelle fragments with similar $T_{\mathrm{c}}$ values, i.e., $\mathrm{PFS}_{26}$-b-PNIPAM ${ }_{190}\left(T_{\mathrm{c}}=61{ }^{\circ} \mathrm{C}\right)$ and $\mathrm{PFS}_{35}-b-\mathrm{P}^{2} \mathrm{VP}_{400}\left(T_{\mathrm{c}}=67^{\circ} \mathrm{C}\right)$. After annealing this mixture at $40{ }^{\circ} \mathrm{C}$ (i.e., $T_{\mathrm{a}}<T_{\mathrm{c}}$ ), both fragments could be clearly distinguished in TEM images (Fig. 2a and S7a $\dagger$ ), as the $\mathrm{PFS}_{35^{-}} b$ $\mathrm{P}_{2} \mathrm{VP}_{400}$ micelles look darker and thicker than $\mathrm{PFS}_{26}-b$ PNIPAM $_{190}$ micelles. After annealing at $60^{\circ} \mathrm{C}$, some tadpole-like micelles could be observed (Fig. $2 \mathrm{~b}$ and S7b广) with a thicker $\mathrm{PFS}_{35}-b-\mathrm{P}_{2} \mathrm{VP}_{400}$ head and a thin $\mathrm{PFS}_{26}-b$-PNIPAM 190 tail. When $T_{\mathrm{a}}=70{ }^{\circ} \mathrm{C}$, patchy micelles were obtained, characterized by local microphase separation between P2VP and PNIPAM chains (Fig. 2c and S7 $\mathrm{c}^{\dagger}$ ). Further increase in $T_{\mathrm{a}}$ resulted in longer patchy comicelles (Fig. 2d-f, S7d and e $\dagger$ ). Therefore, the length of the patchy comicelles could be controlled by $T_{\mathrm{a}}$ in the range of 70 to $90{ }^{\circ} \mathrm{C}$ (Fig. $2 \mathrm{f}$ and $\mathrm{S} 8{ }^{\dagger}$ ).

Since the $T_{\mathrm{c}}$ values of $\mathrm{PFS}_{26}-b$-PNIPAM 190 and $\mathrm{PFS}_{35}-b$ $\mathrm{P}_{2} \mathrm{VP}_{400}$ fragments are similar, about half of both fragments

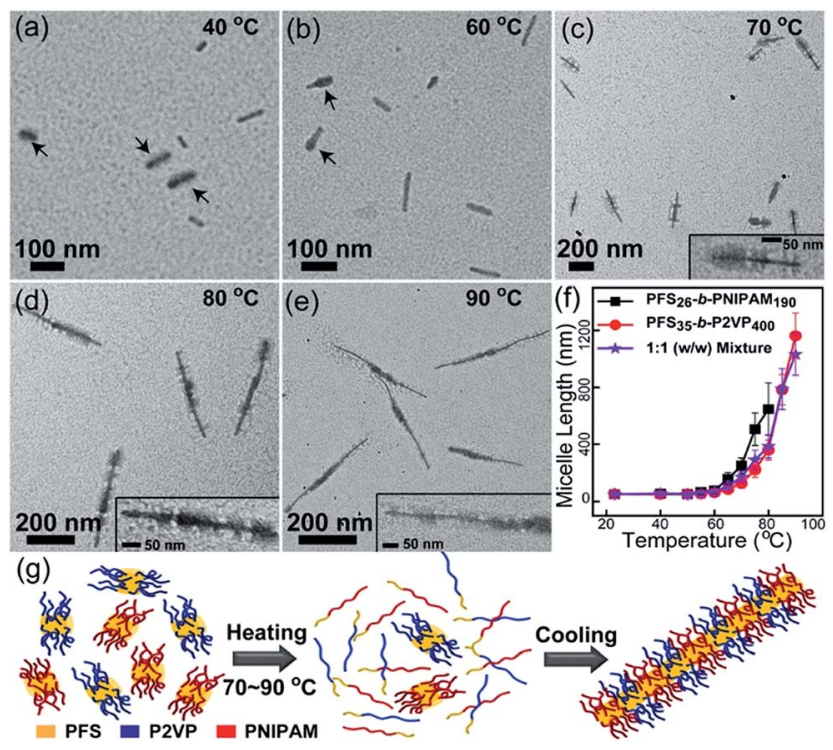

Fig. 2 Self-seeding behaviour of a PFS $26-b-$ PNIPAM $_{190}$ and $\mathrm{PFS}_{35}-b-$ $\mathrm{P}_{2 V P_{400}}$ micelle fragment mixture (mass ratio $1: 1$ ). (a-e) TEM images of the micelles obtained by annealing the mixture at 40 to $90{ }^{\circ} \mathrm{C}$. Arrows in (a) indicate $\mathrm{PFS}_{35}-b-\mathrm{P}_{2} \mathrm{VP}_{400}$ fragments. Arrows in (b) indicate tadpole-like comicelles. The insets in (c-e) show magnified TEM images. (f) shows the change in comicelle length as a function of $T_{\mathrm{a}}$. $(\mathrm{g})$ is a schematic diagram of the self-seeding process of the mixture. These structures are further confirmed by selectively staining the P2VP chains with PtNPs (see Fig. S7†). 
simultaneously dissolve into unimers upon heating to $T_{\mathrm{c}}$, while the rest survive (Fig. S9 and Table S1 $\dagger$ ). Upon cooling to room temperature, both unimers add competitively to the surviving fragments. In this step, the growth rates of unimers dominate the morphology of the comicelles. In our previous work, we demonstrated that similar epitaxial growth rates resulted in the formation of patchy comicelles, while significantly dissimilar growth rates led to block comicelles. We also showed that the epitaxial growth rates of $\mathrm{PFS}_{26}-b$-PNIPAM 190 and $\mathrm{PFS}_{35}-b$ $\mathrm{P}^{2} \mathrm{VP}_{400}$ were similar. ${ }^{28}$ Therefore, in the cooling stage of the self-seeding process for this mixture, both unimers, which come from the dissolution of micelle fragments, add to the surviving seeds at similar rates, resulting in the formation of patchy comicelles (Fig. 2c-e). At higher $T_{\mathrm{a}}$, more micelle fragments dissolved, leading to fewer seeds and more unimers, and thus longer patchy comicelles.

We then examined the self-seeding behaviour of fragments having similar $T_{\mathrm{c}}$ values but very different unimer epitaxial growth rates (Fig. 3). $\mathrm{PFS}_{26}-b$-PNIPAM ${ }_{520}\left(T_{\mathrm{c}}=65^{\circ} \mathrm{C}\right)$ and $\mathrm{PFS}_{35^{-}}$ $b$-P2VP $400\left(T_{\mathrm{c}}=67^{\circ} \mathrm{C}\right)$ micelle fragments have similar $T_{\mathrm{c}}$ values, but the growth rate of $\mathrm{PFS}_{26}-b$-PNIPAM ${ }_{520}$ unimer is much slower than that of $\mathrm{PFS}_{35}-b$-P2 $2 \mathrm{VP}_{400}$ unimer. ${ }^{28}$ After annealing the solution at $60{ }^{\circ} \mathrm{C}$, both micelle fragments could still be distinguished, and their average length $\left(L_{\mathrm{n}}=56 \mathrm{~nm}\right)$ did not change significantly (Fig. S10a $\dagger$ ). However, when the mixture was annealed at 70 to $90{ }^{\circ} \mathrm{C}$, comicelles with a thick middle block flanked by thin tips could be observed $\left(70{ }^{\circ} \mathrm{C}: L_{\mathrm{n}}=81 \mathrm{~nm}\right.$, Fig. S10b; $\dagger 80{ }^{\circ} \mathrm{C}: L_{\mathrm{n}}=210 \mathrm{~nm}$, Fig. $3 \mathrm{a} ; 90{ }^{\circ} \mathrm{C}: L_{\mathrm{n}}=731 \mathrm{~nm}$, Fig. 3b). After selectively staining the P2VP chains with platinum nanoparticles (PtNPs), symmetric triblock comicelles with

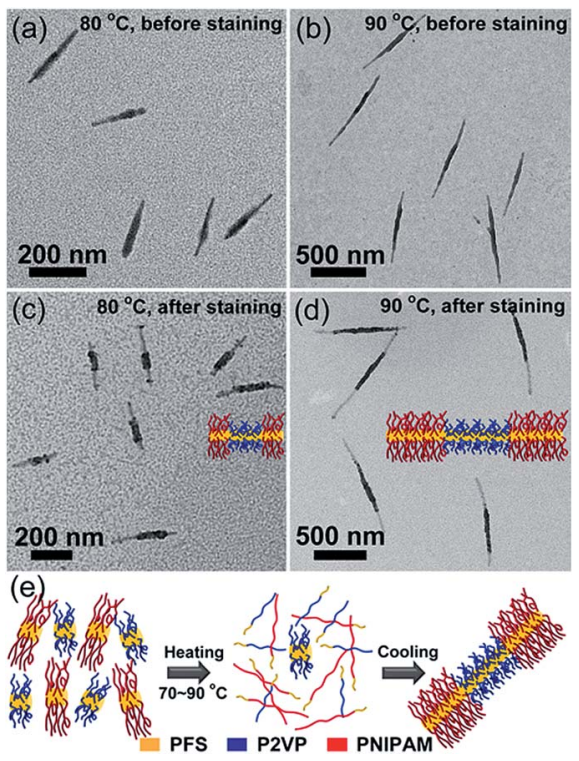

Fig. 3 Self-seeding behaviour of $\mathrm{PFS}_{26}-b-\mathrm{PNIPAM}_{520}$ and $\mathrm{PFS}_{35}-b-$ $\mathrm{P}_{2 V P_{400}}$ fragment mixtures (mass ratio $1: 1$ ). (a-d) TEM images of the micelles obtained by annealing the mixture for $30 \mathrm{~min}$ at ( $\mathrm{a}$ and $\mathrm{c}$ ) $80^{\circ} \mathrm{C}$, and (b and d) $90^{\circ} \mathrm{C}$. (a) and (b) show the comicelles before staining, while (c) and (d) show the comicelles after selectively staining the P2VP block with PtNPs. (e) Schematic diagram of the self-seeding process of the mixture.
$\mathrm{PFS}_{35}-b-\mathrm{P}_{2} \mathrm{VP}_{400}$ as the middle block and $\mathrm{PFS}_{26}-b-\mathrm{PNIPAM}_{520}$ as the end blocks could be clearly distinguished (Fig. 3c-d and S10f-h $\dagger$ ).

Upon heating above $T_{\mathrm{c}}$, both $\mathrm{PFS}_{35}-b$-P2VP 400 and $\mathrm{PFS}_{26}-b$ PNIPAM $_{520}$ fragments dissolved into unimers, which then regrew onto the surviving seeds upon cooling. Since the

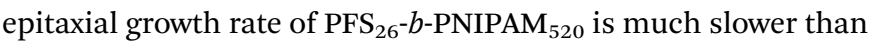
that of $\mathrm{PFS}_{35}-b-\mathrm{P} 2 \mathrm{VP}_{400},{ }^{28}$ most of $\mathrm{PFS}_{35}-b-\mathrm{P} 2 \mathrm{VP}_{400}$ added onto the seed micelles before PFS $_{26}-b$-PNIPAM ${ }_{520}$. After consumption of $\mathrm{PFS}_{35}-b-\mathrm{P}_{2} \mathrm{VP}_{400}$, the growth of $\mathrm{PFS}_{26}-b$-PNIPAM ${ }_{520}$ dominated the growth process, resulting in symmetric $\mathrm{BAB}$ block comicelles with $\mathrm{PFS}_{35}-b$-P2 $2 \mathrm{VP}_{400}$ as the A blocks and $\mathrm{PFS}_{26}-b$ PNIPAM $_{520}$ as the B blocks.

Then we carried out self-seeding experiments with mixed fragments having very different $T_{\mathrm{c}}$, i.e., $\mathrm{PFS}_{17}-b-\mathrm{P}_{2} \mathrm{VP}_{170}\left(L_{0}=\right.$ $\left.43 \mathrm{~nm}, T_{\mathrm{c}}=35{ }^{\circ} \mathrm{C}\right)$ and $\mathrm{PFS}_{26}-b$-PNIPAM ${ }_{190}$ fragments $\left(L_{0}=\right.$ $52 \mathrm{~nm}, T_{\mathrm{c}}=61{ }^{\circ} \mathrm{C}$ ). These two BCP unimers have similar epitaxial growth rates (Fig. S11-S13†). The large difference in $T_{\mathrm{c}}$ values $\left(\Delta T_{\mathrm{c}}=26{ }^{\circ} \mathrm{C}\right)$ makes it possible to manipulate the dissolution sequence of fragments by carefully controlling $T_{\mathrm{a}}$. Fig. 4 shows the morphology evolution of comicelles as $T_{\mathrm{a}}$ was increased. No changes could be observed at $30{ }^{\circ} \mathrm{C}$ (Fig. 4a). When $T_{\mathrm{a}}=40{ }^{\circ} \mathrm{C}$, there are a small fraction of matchstick-like comicelles with a $\mathrm{PFS}_{17}-b-\mathrm{P}_{2} \mathrm{VP}_{170}$ head $(\sim 28 \mathrm{~nm})$ and a $\mathrm{PFS}_{26}{ }^{-}$ $b$-PNIPAM ${ }_{190}$ stick ( $\left.\sim 55 \mathrm{~nm}\right)$ (Fig. 4b), along with $\mathrm{PFS}_{17}-b$ $\mathrm{P}_{2} \mathrm{VP}_{170}$ and $\mathrm{PFS}_{26}-b$-PNIPAM $_{190}$ homomicelles. After annealing at 50 and $60{ }^{\circ} \mathrm{C}$, ABA triblock comicelles were formed with $\mathrm{PFS}_{26}-b$-PNIPAM 190 as the central B block, flanked by $\mathrm{PFS}_{17}-b$ $\mathrm{P}_{2} \mathrm{VP}_{170} \mathrm{~A}$ blocks (Fig. 4c and d). Interestingly, further increasing $T_{\mathrm{a}}$ to $70-80{ }^{\circ} \mathrm{C}$ led to patchy comicelles rather than block comicelles (Fig. $4 \mathrm{e}$ and f).

Due to the large difference in $T_{\mathrm{c}}$ value, the $\mathrm{PFS}_{17}-b-\mathrm{P}_{2} \mathrm{VP}_{170}$ fragments begin to dissolve at lower temperatures. For example at $40{ }^{\circ} \mathrm{C}$, only $57 \%$ of $\mathrm{PFS}_{17}-b$-P2 $\mathrm{VP}_{170}$ fragments survive, but $96 \%$ of $\mathrm{PFS}_{26}-b$-PNIPAM 190 fragments survive (Fig. S9 $\dagger$ and Table S1 $\dagger$ ). Upon cooling, the $\mathrm{PFS}_{17}-b-\mathrm{P}_{2} \mathrm{VP}_{170}$ unimer adds to both $\mathrm{PFS}_{17}-b-\mathrm{P} 2 \mathrm{VP}_{170}$ and $\mathrm{PFS}_{26}-b$-PNIPAM 190 fragments, leading to the formation of longer $\mathrm{PFS}_{17}-b-\mathrm{P}_{2} \mathrm{VP}_{170}$ homomicelles $(\sim 79 \mathrm{~nm})$ and heterogeneous $\mathrm{PFS}_{17}-b-\mathrm{P}_{2} \mathrm{VP}_{170} / \mathrm{PFS}_{26}-b$ PNIPAM $_{190}$ matchstick-like comicelles (Fig. 4b). Although the length of $\mathrm{PFS}_{17}-b-\mathrm{P}_{2} \mathrm{VP}_{170}$ homomicelles increased from $43 \mathrm{~nm}$ to $79 \mathrm{~nm}$, the length of PFS $_{26}-b$-PNIPAM 190 micelles did not change $(\sim 54 \mathrm{~nm}$, Fig. S14 $\dagger)$. For $T_{\mathrm{a}}=50{ }^{\circ} \mathrm{C}, 96 \%$ of $\mathrm{PFS}_{26}-b$ PNIPAM $_{190}$ fragments survive, but only $16 \%$ of $\mathrm{PFS}_{17}-b-\mathrm{P}_{2} \mathrm{VP}_{170}$ fragments persist; whereas at $60{ }^{\circ} \mathrm{C}, 66 \%$ of $\mathrm{PFS}_{26}-b$-PNIPAM 190 fragments survive, but only $6 \%$ of $\mathrm{PFS}_{17}-b-\mathrm{P}_{2} \mathrm{VP}_{170}$ fragments remain (Fig. S9 $\dagger$ and Table $\mathrm{S} 1 \dagger$ ). Therefore, most $\mathrm{PFS}_{17}-b$ $\mathrm{P} 2 \mathrm{VP}_{170}$ fragments dissolve to give unimers at $50-60{ }^{\circ} \mathrm{C}$, which then add to the surviving $\mathrm{PFS}_{26}-b$-PNIPAM ${ }_{190}$ fragments upon cooling, resulting in the formation of block comicelles (Fig. 4g). At higher $T_{\mathrm{a}}$, both $\mathrm{PFS}_{17}-b-\mathrm{P}_{2} \mathrm{VP}_{170}$ and $\mathrm{PFS}_{26}-b$-PNIPAM 190 fragments dissolve to form unimers. For example at $80{ }^{\circ} \mathrm{C}$, all of the $\mathrm{PFS}_{17}-b$-P2VP 170 fragments dissolve while $8 \%$ of $\mathrm{PFS}_{26}-b$ PNIPAM $_{190}$ fragments survive. After cooling to room temperature, both unimers, which have similar growth rates, simultaneously add to the surviving PFS $_{26}-b$-PNIPAM 190 seeds, resulting in the formation of patchy comicelles (Fig. 4g). 

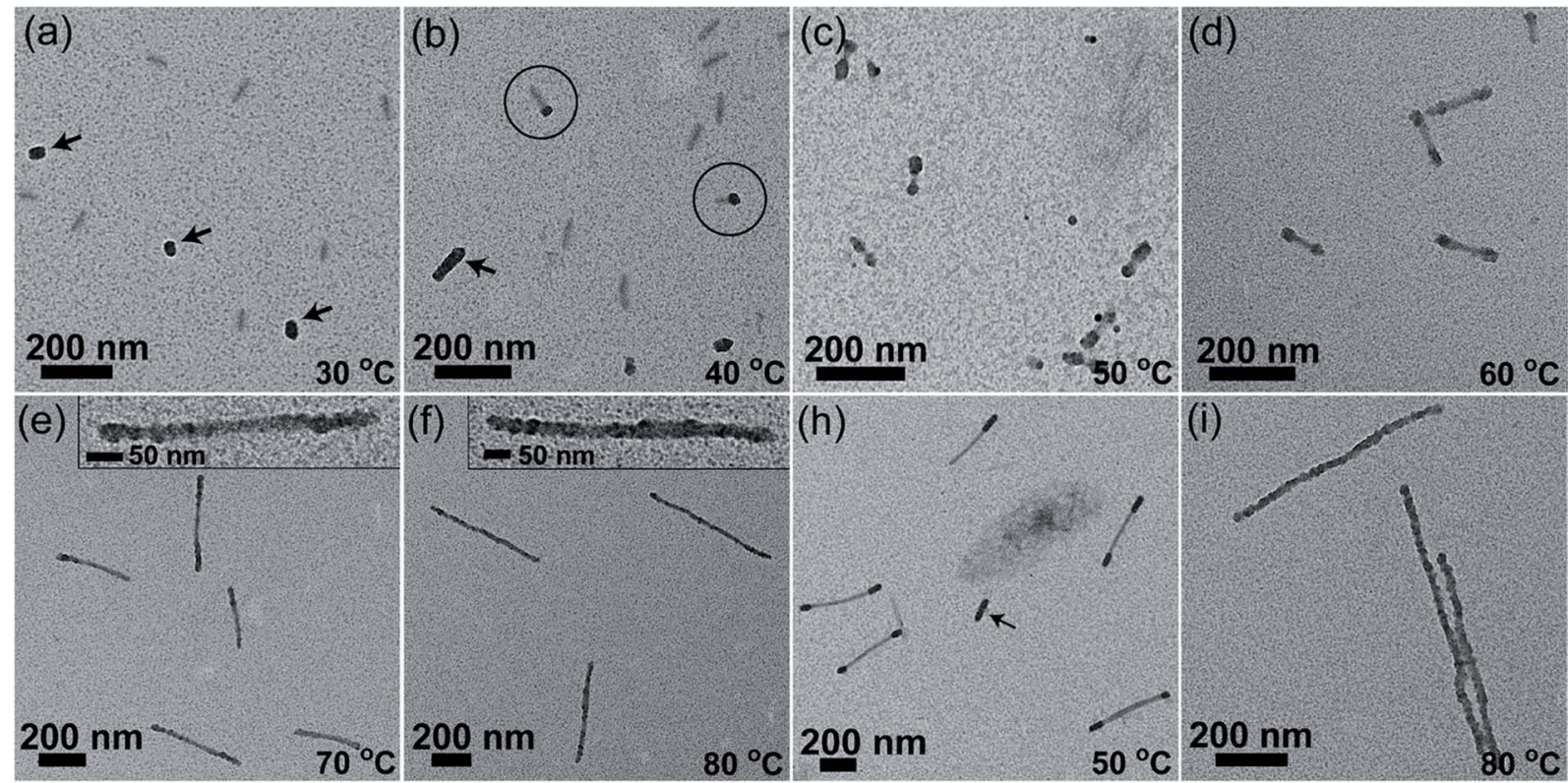

(g)

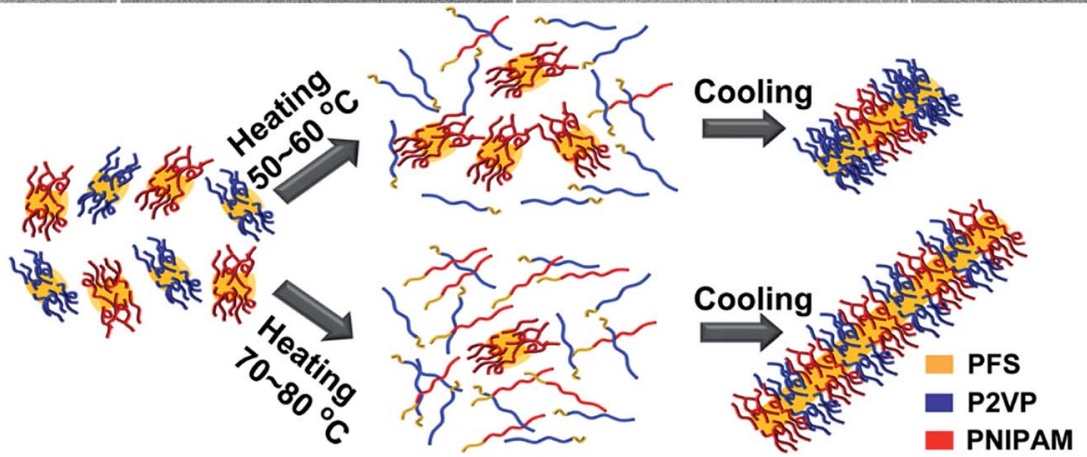

Fig. 4 Self-seeding of a PFS $26-b$-PNIPAM 190 and $P_{F S} 17-b-P 2 V_{170}$ fragment mixture (mass ratio $1: 1$ ). (a-f) TEM images of the micelles obtained by annealing the mixture at 30 to $80{ }^{\circ} \mathrm{C}$. The arrows in (a) indicate the $\mathrm{PFS}_{17}-b-\mathrm{P}_{2} \mathrm{VP}_{170}$ fragments. The arrow in (b) indicates a PFS $17-b-\mathrm{P}_{2} \mathrm{VP} \mathrm{P}_{170}$ homomicelle. The circles in (b) indicate matchstick-like micelles. The insets in (e and f) show magnified TEM images of patchy comicelles. (g) Schematic diagram of the self-seeding process of the fragment mixture. (h and i) TEM images of the micelles obtained by annealing a mixture of $\mathrm{PFS}_{26}-b$-PNIPAM 190 micelles $\left(L_{n}=290 \mathrm{~nm}\right)$ and PFS ${ }_{17}-b-\mathrm{P}_{2} \mathrm{VP}_{170}$ fragments $\left(L_{0}=43 \mathrm{~nm}\right)$ at $(\mathrm{h}) 50{ }^{\circ} \mathrm{C}$ and (i) $80{ }^{\circ} \mathrm{C}$. The arrow in (h) indicates a $\mathrm{PFS}_{17}-b-\mathrm{P}_{2} \mathrm{VP}_{170}$ homomicelle. The P2VP chains were selectively stained with PtNPs.

In order to make the block comicelles shown in Fig. 4c and $\mathrm{d}$ more distinguishable, we conducted a self-seeding experiment at $50{ }^{\circ} \mathrm{C}$ with a $1: 1$ mixture of $\mathrm{PFS}_{26}-b$-PNIPAM ${ }_{190}$ micelles $\left(L_{\mathrm{n}}=\right.$ $290 \mathrm{~nm}$, Fig. S15 $\dagger$ ) and $\mathrm{PFS}_{17}-b-\mathrm{P}_{2} \mathrm{VP}_{170}$ fragments $\left(L_{0}=43 \mathrm{~nm}\right)$. As shown in Fig. $4 \mathrm{~h}$ and S16, $\dagger$ ABA triblock comicelles can be clearly visualized, accompanied by a few $\mathrm{PFS}_{17}-b-\mathrm{P}_{2} \mathrm{VP}_{170}$ homomicelles formed by epitaxial growth on surviving $\mathrm{PFS}_{17}-b-\mathrm{P} 2 \mathrm{VP}_{170}$ seeds. Upon heating to $80^{\circ} \mathrm{C}$, most of the long and short micelles dissolved. The competitive growth of both unimers on the surviving seeds led to the formation of patchy comicelles (Fig. 4i).

\section{Conclusions}

In summary, we found that the morphology of core-crystalline cylindrical micelles could be controlled by manipulating the synergistic self-seeding behaviour of micelle fragment mixtures. The morphology of the comicelles is dependent on (1) the dissolution sequence of micelle fragments, and (2) the epitaxial growth rate of the corresponding unimers. By blending two kinds of micelle fragments with similar $T_{\mathrm{c}}$ values and similar growth rates, patchy micelles with controllable length can be obtained by self-seeding. If the fragments have similar $T_{\mathrm{c}}$ values but very different growth rates, block comicelles are obtained. On the other hand, if micelle fragments with very different $T_{\mathrm{c}}$ are blended, the morphology of comicelles can be controlled by varying the annealing temperature. At lower temperatures, block comicelles are obtained; whereas at higher temperatures, patchy comicelles are formed. Thus, by carefully controlling the dissolution and growth sequence of micelle fragments, both the length and morphology of micelles can be varied. This synergistic self-seeding strategy not only offers a convenient route for preparing comicelles with controllable morphology and uniform length, but also provides a platform for studying the synergistic self-seeding behaviour of polymer seed crystallites.

\section{Conflicts of interest}

There are no conflicts to declare. 


\section{Acknowledgements}

The Toronto authors thank NSERC Canada for their support of this research.

\section{Notes and references}

1 Y. Geng, P. Dalhaimer, S. Cai, R. Tsai, M. Tewari, T. Minko and D. E. Discher, Nat. Nanotechnol., 2007, 2, 249-255.

2 Z. Deng, S. Yuan, R. X. Xu, H. Liang and S. Liu, Angew. Chem., Int. Ed., 2018, 57, 8896-8900.

3 X. Hu, S. Zhai, G. Liu, D. Xing, H. Liang and S. Liu, Adv. Mater., 2018, 30, 1706307.

4 J. M. Dean, N. E. Verghese, H. Q. Pham and F. S. Bates, Macromolecules, 2003, 36, 9267-9270.

5 J. Yuan and A. H. Müller, Polymer, 2010, 51, 4015-4036.

6 D. J. Pochan, J. Zhu, K. Zhang, K. L. Wooley, C. Miesch and T. Emrick, Soft Matter, 2011, 7, 2500-2506.

7 J. Dupont, G. Liu, K. i. Niihara, R. Kimoto and H. Jinnai, Angew. Chem., Int. Ed., 2009, 48, 6144-6147.

8 H. Cui, Z. Chen, S. Zhong, K. L. Wooley and D. J. Pochan, Science, 2007, 317, 647-650.

9 H. Gröschel, A. Walther, T. I. Löbling, F. H. Schacher, H. Schmalz and A. H. Müller, Nature, 2013, 503, 247-251.

10 A. M. Oliver, J. Gwyther, M. A. Winnik and I. Manners, Macromolecules, 2018, 51, 222-231.

11 D. J. Lunn, J. R. Finnegan and I. Manners, Chem. Sci., 2015, 6, 3663-3673.

12 Y. Mai and A. Eisenberg, Chem. Soc. Rev., 2012, 41, 59695985.

13 N. Petzetakis, A. P. Dove and R. K. O'Reilly, Chem. Sci., 2011, 2, 955-960.

14 J. Qian, X. Li, D. J. Lunn, J. Gwyther, Z. M. Hudson, E. Kynaston, P. A. Rupar, M. A. Winnik and I. Manners, J. Am. Chem. Soc., 2014, 136, 4121-4124.

15 B. Fan, R.-Y. Wang, X.-Y. Wang, J.-T. Xu, B.-Y. Du and Z.-Q. Fan, Macromolecules, 2017, 50, 2006-2015.

16 J. B. Gilroy, T. Gädt, G. R. Whittell, L. Chabanne, J. M. Mitchels, R. M. Richardson, M. A. Winnik and I. Manners, Nat. Chem., 2010, 2, 566-570.

17 W. N. He and J. T. Xu, Prog. Polym. Sci., 2012, 37, 1350-1400. 18 H. Qiu, Y. Gao, C. E. Boott, O. E. Gould, R. L. Harniman, M. J. Miles, S. E. Webb, M. A. Winnik and I. Manners, Science, 2016, 352, 697-701.
19 X. Wang, G. Guerin, H. Wang, Y. Wang, I. Manners and M. A. Winnik, Science, 2007, 317, 644-647.

20 J. Schmelz, A. E. Schedl, C. Steinlein, I. Manners and H. Schmalz, J. Am. Chem. Soc., 2012, 134, 14217-14225.

21 M. C. Arno, M. Inam, Z. Coe, G. Cambridge, L. J. Macdougall, R. Keogh, A. P. Dove and R. K. O'Reilly, J. Am. Chem. Soc., 2017, 139, 16980-16985.

22 D. Tao, C. Feng, Y. Cui, X. Yang, I. Manners, M. A. Winnik and X. Huang, J. Am. Chem. Soc., 2017, 139, 7136-7139.

23 A. Nazemi, X. He, L. R. MacFarlane, R. L. Harniman, M.-S. Hsiao, M. A. Winnik, C. F. Faul and I. Manners, J. Am. Chem. Soc., 2017, 139, 4409-4417.

24 M. Inam, G. Cambridge, A. Pitto-Barry, Z. P. Laker, N. R. Wilson, R. T. Mathers, A. P. Dove and R. K. O'Reilly, Chem. Sci., 2017, 8, 4223-4230.

25 H. Qiu, Y. Gao, V. A. Du, R. Harniman, M. A. Winnik and I. Manners, J. Am. Chem. Soc., 2015, 137, 2375-2385.

26 G. Cambridge, G. Guerin, I. Manners and M. A. Winnik, Macromol. Rapid Commun., 2010, 31, 934-938.

27 J. R. Finnegan, D. J. Lunn, O. E. C. Gould, Z. M. Hudson, G. R. Whittell, M. A. Winnik and I. Manners, J. Am. Chem. Soc., 2014, 136, 13835-13844.

28 J. Xu, H. Zhou, Q. Yu, I. Manners and M. A. Winnik, J. Am. Chem. Soc., 2018, 140, 2619-2628.

29 J. Qian, Y. Lu, A. Chia, M. Zhang, P. A. Rupar, N. Gunari, G. C. Walker, G. Cambridge, F. He, G. Guerin, I. Manners and M. A. Winnik, ACS Nano, 2013, 7, 3754-3766.

30 J. S. Qian, G. Guerin, Y. J. Lu, G. Cambridge, I. Manners and M. A. Winnik, Angew. Chem., Int. Ed., 2011, 50, 1622-1625.

31 D. Blundell, A. Keller and A. Kovacs, J. Polym. Sci., Part B: Polym. Lett., 1966, 4, 481-486.

32 J. Xu, Y. Ma, W. Hu, M. Rehahn and G. Reiter, Nat. Mater., 2009, 8, 348-353.

33 W. N. He, B. Zhou, J.-T. Xu, B.-Y. Du and Z.-Q. Fan, Macromolecules, 2012, 45, 9768-9778.

34 D. Tao, C. Feng, Y. Lu, Y. Cui, X. Yang, I. Manners, M. A. Winnik and X. Huang, Macromolecules, 2018, 51, 2065-2075.

35 X. Li, B. Jin, Y. Gao, D. W. Hayward, M. A. Winnik, Y. Luo and I. Manners, Angew. Chem., Int. Ed., 2016, 55, 11392-11396.

36 G. Guerin, P. A. Rupar, I. Manners and M. A. Winnik, Nat. Commun., 2018, 9, 1158. 